\title{
Prevalence of and risk factors for childhood overweight and obesity
}

\author{
Paul J. Veugelers, Angela L. Fitzgerald
}

Abstract

Background: Increases in childhood overweight and obesity have become an important public health problem in industrialized nations. Preventive public health action is required, but more research of risk factors is required before evidence-based initiatives can be developed and targeted effectively. We investigated the association between childhood overweight and obesity and risk factors relating to dietary habits, actitivities, parents and schools.

Methods: In 2003 we surveyed grade 5 students and their parents and school principals in Nova Scotia. We measured height and weight and assessed dietary habits (using Harvard's Youth/Adolescent Food Frequency Questionnaire), physical and sedentary activities, and parental and school-based risk factors. We estimated neighbourhood income by averaging, per school, the postal-code level means of household income of residential addresses of children attending that school. We used multilevel logistic regression to evaluate the significance of these risk factors for overweight and obesity.

Results: On the basis of measurements taken of 4298 grade 5 students, we estimated the provincial prevalence of overweight to be $32.9 \%$ and of obesity to be $9.9 \%$. Children who bought lunch at school were at increased risk of overweight (fully adjusted odds ratio [OR] 1.39, 95\% confidence interval $[\mathrm{Cl}]$ 1.16-1.67), whereas those who ate supper together with their family 3 or more times a week were at decreased risk (OR $0.68,95 \%$ Cl 0.52-0.88). Physical education classes 2 or more times a week at school were associated with a decreased risk of overweight (OR $0.61,95 \% \mathrm{Cl} 0.43-0.87$ ) and obesity (OR $0.54,95 \% \mathrm{Cl} 0.33-0.88)$. Children in high-income neighbourhoods were half as likely to be obese as their peers living in low-income neighbourhoods (OR 0.50, 95\% Cl 0.36-0.70).

Interpretation: Parents and schools provide important opportunities for public health initiatives for reducing childhood overweight and obesity. Children and schools in low-income neighbourhoods should receive priority in public health initiatives to reduce future socioeconomic inequalities in health.

CMAJ 2005;173(6):607-13

I ncreases in childhood overweight and obesity have become a major public health problem in industrialized nations. ${ }^{1,2}$ In Canada, rates of overweight and obesity among children have more than doubled in past decades, with the most recent estimates indicating that about 30\% of children are overweight or obese., ${ }^{3,4}$ The numerous psy- chosocial, physical and economic consequences of overweight and obesity are well-known. Childhood overweight affects self-esteem and has negative consequences on cognitive and social development. ${ }^{5,6}$ Conditions such as type 2 diabetes mellitus, hypertension and hypercholesterolemia, which were previously seen primarily in adults, are becoming more common among children as the prevalence of obesity increases. ${ }^{7}$ Because childhood overweight often persists into adulthood, a rising number of adults will be at increased risk of these conditions as well as of cardiovascular disease, osteoarthritis and certain types of cancer. ${ }^{8,9}$ As a whole, the obesity epidemic constitutes a substantial decrease in quality of life and life expectancy and accounts for billions of dollars in health care spending. ${ }^{10,11}$

Insufficient physical activity and poor nutrition are widely acknowledged as the primary mechanisms underlying the rise in excess body weight. ${ }^{12}$ Recent studies have described geographic and socioeconomic gradients and identified aspects of children's lifestyle, including physical and sedentary activities, as risk factors for overweight and obesity. ${ }^{13-20}$ Most recently, Swinburn and colleagues identified risk factors related to parents, family and school as potentially significant and as requiring more evidence so that evidence-based policy and program decision-making for the prevention of excess weight can be developed. ${ }^{21}$ The need for further research is underlined by the fact that a number of schools and jurisdictions in Canada are already implementing policies and programs without evidence of their effectiveness.

In 2003, we conducted a comprehensive survey of risk factors for childhood overweight and obesity with grade 5 students and their parents and school principals in Nova Scotia, a province with particular weight and health concerns among both children and adults. ${ }^{13,22,23}$ Here, we evaluate the prevalence of overweight and obesity and examine the contribution of dietary habits, activities and sociodemographic and school-based factors to weight problems among children.

\section{Methods}

The 2003 Children's Lifestyle and School-performance Study (CLASS) was a survey of grade 5 students in Nova Scotia on health, nutrition and lifestyle factors. The procedures used in this study are briefly described below and in more detail elsewhere..$^{24,25}$ 
We measured standing height to the nearest $0.1 \mathrm{~cm}$ after students had removed their shoes and body weight to the nearest $0.1 \mathrm{~kg}$ on calibrated digital scales. Overweight and obesity were defined using the international body mass index cut-off points established for children and youth. ${ }^{26}$ These cut-off points are based on healthrelated adult definitions of overweight $\left(\geq 25 \mathrm{~kg} / \mathrm{m}^{2}\right)$ and obesity $\left(\geq 30 \mathrm{~kg} / \mathrm{m}^{2}\right)$ but are adjusted to specific age and sex categories for children. ${ }^{26}$

The CLASS survey included a modified version of Harvard's Youth/Adolescent Food Frequency Questionnaire, ${ }^{27}$ which gathers information on both dietary intake and habits pertaining to mealtime behaviours. It also included validated questions on the frequency of physical activities and the number of hours of sedentary activities (watching television, working on a computer, playing video games) taken from the National Longitudinal Survey of Children and Youth (NLSCY). ${ }^{28}$ Information on sociodemographic factors was taken from a survey completed by parents and included the child's sex, place of birth and residency, as well as the parents' marital status, income level and educational attainment. The children's ages were not included, since the vast majority of grade 5 students were either 10 or 11 years old at the time they completed the CLASS survey.

We estimated neighbourhood income by averaging, per school, the postal-code level means of household income (avail- able through the 2001 Canada census) of residential addresses of children attending that school. Finally, we developed and administered a short survey for school principals to collect information on school characteristics, including sales of soft drinks, presence of vending machines, type of food services, frequency of physical education classes and possible financial restraints for recreation and gymnasium equipment.

Because our observations of students are nested within those of their schools, we assessed student and school-based factors at distinct levels using multilevel statistical methods. Specifically, student and parental factors were considered as first-level covariates. All school characteristics and neighbourhood income were considered as contextual factors and treated as second-level covariates. We first applied multilevel logistic regression methods to determine to what extent risk factors were associated with overweight or obesity. Second, we grouped each risk factor into 1 of 4 groups - dietary habits, activities, and sociodemographic and school-based factors - and then adjusted for all significant risk factors within each group. These estimates are referred to as theme-adjusted odds ratios. Third, we considered all significant risk factors simultaneously to quantify their independent importance for excess body weight.

Because participation rates were slightly lower in residential areas with lower estimates of household income, we calculated re-

Table 1: Dietary habit-related risk factors for overweight among grade 5 students in Nova Scotia

\begin{tabular}{|c|c|c|c|c|c|}
\hline \multirow[b]{2}{*}{ Risk factor } & \multirow{2}{*}{$\begin{array}{l}\text { No. of } \\
\text { students }\end{array}$} & \multirow{2}{*}{$\begin{array}{c}\text { Weighted } \\
\text { prevalence, }{ }^{*} \%\end{array}$} & \multicolumn{3}{|c|}{ Weighted odds ratio (95\% confidence interval)* } \\
\hline & & & Unadjusted & Theme-adjusted $\dagger$ & Fully adjusted $\neq$ \\
\hline Breakfast & $n=4209$ & & & & \\
\hline Usually eats & 4054 & 96.3 & 1 & - & - \\
\hline Does not eat & 155 & 3.7 & $1.50(1.06-2.13)$ & - & - \\
\hline Lunch & $n=4061$ & & & & \\
\hline Bring from home & 2547 & 61.7 & 1 & 1 & 1 \\
\hline Eat at home & 647 & 17.5 & $0.94(0.77-1.14)$ & $0.93(0.77-1.13)$ & $0.99(0.82-1.19)$ \\
\hline Buy at school & 805 & 19.3 & $1.47(1.23-1.76)$ & $1.43(1.19-1.71)$ & $1.39(1.16-1.67)$ \\
\hline Does not eat & 62 & 1.5 & $1.19(0.69-2.05)$ & $1.10(0.64-1.89)$ & $1.08(0.63-1.86)$ \\
\hline Family supper & $n=4242$ & & & & \\
\hline$<$ once/wk & 507 & 12.0 & 1 & 1 & 1 \\
\hline 1-2 times/wk & 643 & 15.3 & $0.81(0.63-1.03)$ & $0.83(0.65-1.06)$ & $0.81(0.63-1.04)$ \\
\hline 3-4 times/wk & 575 & 13.5 & $0.67(0.52-0.87)$ & $0.71(0.54-0.94)$ & $0.68(0.52-0.88)$ \\
\hline$\geq 5$ times/wk & 2517 & 59.2 & $0.69(0.57-0.84)$ & $0.78(0.63-0.97)$ & $0.75(0.61-0.91)$ \\
\hline $\begin{array}{l}\text { Supper in front of } \\
\text { television }\end{array}$ & $n=4256$ & & & & \\
\hline$<$ once/wk & 1876 & 44.2 & 1 & 1 & - \\
\hline 1-2 times/wk & 1369 & 31.9 & $1.07(0.93-1.23)$ & $1.06(0.92-1.22)$ & - \\
\hline 3-4 times/wk & 478 & 11.4 & $1.22(1.00-1.50)$ & $1.14(0.93-1.41)$ & - \\
\hline$\geq 5$ times/wk & 533 & 12.5 & $1.44(1.18-1.74)$ & $1.26(1.01-1.28)$ & - \\
\hline $\begin{array}{l}\text { Eat at fast food } \\
\text { restaurant }\end{array}$ & $n=4241$ & & & & \\
\hline$<$ once/wk & 2241 & 52.8 & 1 & - & - \\
\hline 1-2 times/wk & 1835 & 43.3 & $1.02(0.90-1.16)$ & - & - \\
\hline$\geq 3$ times/wk & 165 & 3.9 & $0.86(0.57-1.12)$ & - & - \\
\hline
\end{tabular}

*Weighted for nonresponse bias to reflect provincial estimates.

†Theme-adjusted odds ratios are adjusted for lunch, family supper and supper in front of the television.

FFully adjusted odds ratios are adjusted for significant risk factors in all 4 theme groups, including lunch and family supper in dietary habits, participation in physical activities in activities (Table 2), parental education and neighbourhood income in sociodemographic factors (Table 3 ), and frequency of physical education classes in school-based factors (Table 4). 
sponse weights to overcome potential nonresponse bias. On the basis of average household incomes according to postal code data from the 2001 census for both participants and nonparticipants, we calculated response rates per decile of household incomes by postal code. These response rates were subsequently converted into response weights. Because we weighted all prevalence and risk estimates for nonresponse bias, they represent provincial population estimates for grade 5 students. We considered missing values as separate covariate categories, but we do not present their estimated values.

This study, including data collection and parental informed consent forms, was approved by the health sciences human research ethics board of Dalhousie University.

\section{Results}

Of the 291 public schools in Nova Scotia with grade 5 classes, 282 (96.9\%) participated in the study. Parental consent was received for 5517 students, which provided an average response rate of $51.1 \%$ per school. One of the 7 provincial school boards did not allow measurements of height and weight. Students without height and weight measurements were excluded from the analyses, leaving a sample of 4298 children from 242 schools.

The prevalence of overweight among grade 5 students in Nova Scotia in 2003 was $32.9 \%$, with $9.9 \%$ being obese. The prevalence of overweight was about the same for girls $(32.9 \%)$ and boys $(33.0 \%)$, whereas the prevalence of obesity was lower among girls $(9.0 \%)$ than among boys (10.9\%).

Among grade 5 students, $3.7 \%$ did not eat breakfast (Table 1). In a univariate analysis, these students were 1.5 times (or 50\%) more likely to be overweight than students who usually ate breakfast. Missing lunch was also associated with an increased risk of excess body weight, but this risk was not statistically significant. Relative to those bringing their lunch from home, children buying lunch at school were $47 \%$ more likely to be overweight (unadjusted odds ratio [OR] 1.47, 95\% confidence interval [CI $1.23-1.76)$. Increasing frequencies of eating supper together at home (family supper) and decreasing frequencies of eating supper in front of the television were associated with a decreased risk of overweight. Because dietary habits are interrelated, we considered these habits simultaneously and found that lunch pattern and frequency of family supper and supper in front of the television were determinants of body weight (Table 1: themeadjusted ORs). After adjusting for all significant risk factors across all 4 theme groups, only buying lunch at school significantly increased the risk of overweight, and family suppers both 3-4 and 5 or more times a week significantly decreased the risk (Table 1: fully adjusted ORs).

Sedentary activity of more than 1 hour per day was as-

Table 2: Activity-related risk factors for overweight among grade 5 students in Nova Scotia

\begin{tabular}{|c|c|c|c|c|c|}
\hline \multirow[b]{2}{*}{ Risk factor } & \multirow{2}{*}{$\begin{array}{l}\text { No. of } \\
\text { students }\end{array}$} & \multirow{2}{*}{$\begin{array}{c}\text { Weighted } \\
\text { prevalence, } * \%\end{array}$} & \multicolumn{3}{|c|}{ Weighted odds ratio (95\% confidence interval)* } \\
\hline & & & Unadjusted & Theme-adjusted $\dagger$ & Fully adjusted $\neq$ \\
\hline $\begin{array}{l}\text { Participation in } \\
\text { physical activities }\end{array}$ & $n=4280$ & & & & \\
\hline$\leq$ twice/wk & 568 & 13.5 & 1 & 1 & 1 \\
\hline$>2$ and $\leq 4$ times/wk & 990 & 23.2 & $0.87(0.71-1.06)$ & $0.87(0.71-1.06)$ & $0.93(0.76-1.15)$ \\
\hline$>4$ and $\leq 7$ times/wk & 2289 & 53.2 & $0.85(0.70-1.02)$ & $0.86(0.71-1.03)$ & $0.89(0.70-1.08)$ \\
\hline$>7$ times/wk & 433 & 10.1 & $0.68(0.52-0.89)$ & $0.70(0.54-0.91)$ & $0.74(0.56-0.97)$ \\
\hline $\begin{array}{l}\text { Participation in } \\
\text { sedentary activities } \neq\end{array}$ & $n=4270$ & & & & \\
\hline$\leq 1$ hour/d & 452 & 10.5 & 1 & 1 & - \\
\hline$>1$ and $\leq 3 \mathrm{hr} / \mathrm{d}$ & 1760 & 41.0 & $1.28(1.02-1.61)$ & $1.28(1.02-1.61)$ & - \\
\hline$>3$ and $\leq 6 \mathrm{hr} / \mathrm{d}$ & 1210 & 28.5 & $1.32(1.04-1.70)$ & $1.30(1.02-1.65)$ & - \\
\hline$>6 \mathrm{hr} / \mathrm{d}$ & 848 & 20.0 & $1.37(1.06-1.77)$ & $1.35(1.04-1.74)$ & - \\
\hline $\begin{array}{l}\text { Travel to and from } \\
\text { school }\end{array}$ & $n=4000$ & & & & \\
\hline Walk or bike & 1224 & 31.7 & 1 & 1 & - \\
\hline Driven $<15$ min & 1580 & 39.0 & $1.15(0.96-1.37)$ & $1.15(0.96-1.37)$ & - \\
\hline $\begin{array}{l}\text { Driven }>15 \text { and } \\
<30 \text { min }\end{array}$ & 852 & 28.8 & $1.20(0.97-1.49)$ & $1.20(0.97-1.48)$ & - \\
\hline Driven $>30 \mathrm{~min}$ & 344 & 8.5 & $1.39(1.05-1.85)$ & $1.38(1.04-1.84)$ & - \\
\hline
\end{tabular}

*Weighted for nonresponse bias to reflect provincial estimates.

†Theme-adjusted odds ratios are adjusted for participation in physical activities, participation in sedentary activities, and travel to and from school.

¥Fully adjusted odds ratios are adjusted for significant risk factors in all 4 theme groups, including lunch and family supper in dietary habits (Table 1), participation in physical activities in activities, parental education and neighbourhood income in sociodemographic factors (Table 3), and frequency of physical education classes in school-based factors (Table 4).

$¥$ Sedentary activities include watching television, using a computer and playing video games. 
sociated with a significantly increased risk of overweight, as was being driven to school longer than 30 minutes (Table 2: theme-adjusted ORs). Participating in physical activity more than 7 times a week was associated with a decreased risk of overweight (Table 2: theme-adjusted ORs). When considered in conjunction with other determinants, frequency of physical activity appears to be the only activity-related factor independently associated with overweight. However, sedentary activity was independently associated with overweight when physical activity was not considered (data not shown), which indicates a correlation between these 2 covariates.

With respect to sociodemographic factors, children whose parents had attained higher levels of education and had an income over $\$ 60000$ were at a decreased risk of overweight, as were children who resided in urban areas and who resided in neighbourhoods where the income was in the middle or highest one-third (Table 3).

Of all children, $29.3 \%$ attended schools where lunches were provided by a foodservice company. This may include on-site catering or fast food delivery. Children attending such schools were $12 \%$ more likely to be overweight than children who attended schools where no foodservice companies were used, but this difference was not statistically significant (Table 4). Also, no substantial or statistically significant differences were observed among children attending schools where lunches were distributed by staff and volunteers or as part of a prepaid lunch program.

Of all children, $15.3 \%$ attended schools where soft

Table 3: Sociodemographic risk factors for overweight among grade 5 students in Nova Scotia

\begin{tabular}{|c|c|c|c|c|c|}
\hline \multirow[b]{2}{*}{ Risk factor } & \multirow{2}{*}{$\begin{array}{l}\text { No. of } \\
\text { students }\end{array}$} & \multirow{2}{*}{$\begin{array}{c}\text { Weighted } \\
\text { prevalence, } * \%\end{array}$} & \multicolumn{3}{|c|}{ Weighted odds ratio (95\% confidence interval) } \\
\hline & & & Unadjusted & Theme-adjusted $\dagger$ & Fully adjusted $\neq$ \\
\hline Sex & $n=4298$ & & & & \\
\hline Female & 2180 & 50.5 & 1 & & \\
\hline Male & 2118 & 49.5 & $1.01(0.90-1.13)$ & - & - \\
\hline Place of birth & $n=4002$ & & & & \\
\hline Nova Scotia & 3508 & 87.6 & 1 & - & - \\
\hline Other & 494 & 12.4 & $0.94(0.77-1.15)$ & - & - \\
\hline Parents' marital status & $n=3961$ & & & & \\
\hline $\begin{array}{l}\text { Married or common } \\
\text { law }\end{array}$ & 3307 & 83.0 & 1 & - & - \\
\hline Separated or divorced & 459 & 11.7 & $1.21(1.00-1.47)$ & - & - \\
\hline Single or widowed & 195 & 5.3 & $1.11(0.83-1.49)$ & - & - \\
\hline Parental education & $n=3985$ & & & & \\
\hline $\begin{array}{l}\text { Completed secondary } \\
\text { school or less }\end{array}$ & 1179 & 30.1 & 1 & 1 & 1 \\
\hline $\begin{array}{l}\text { Completed } \\
\text { community college }\end{array}$ & 1502 & 37.6 & $0.87(0.73-1.03)$ & $0.91(0.76-1.08)$ & $0.90(0.76-1.07)$ \\
\hline Completed university & 934 & 23.1 & $0.67(0.55-0.82)$ & $0.76(0.61-0.94)$ & $0.73(0.60-0.89)$ \\
\hline $\begin{array}{l}\text { Completed graduate } \\
\text { university }\end{array}$ & 370 & 9.2 & $0.64(0.49-0.84)$ & $0.75(0.57-0.99)$ & $0.73(0.56-0.96)$ \\
\hline Parental income, \$ & $n=3324$ & & & & \\
\hline$<20000$ & 339 & 10.8 & 1 & 1 & - \\
\hline $20000-40000$ & 736 & 22.5 & $0.94(0.71-1.24)$ & $0.97(0.74-1.29)$ & - \\
\hline $40000-60000$ & 884 & 26.4 & $0.83(0.64-1.07)$ & $0.90(0.69-1.18)$ & - \\
\hline$>60000$ & 1365 & 40.3 & $0.62(0.48-0.80)$ & $0.73(0.56-0.95)$ & - \\
\hline \multicolumn{6}{|l|}{ Neighbourhood income $₫$} \\
\hline Lowest one-third & - & - & 1 & 1 & 1 \\
\hline Middle one-third & - & - & $0.78(0.64-0.99)$ & $0.84(0.69-1.03)$ & $0.80(0.66-0.98)$ \\
\hline Highest one-third & - & - & $0.71(0.57-0.87)$ & $0.82(0.66-1.00)$ & $0.76(0.62-0.95)$ \\
\hline Residence location & $n=4298$ & & & & \\
\hline Rural & 1700 & 38.3 & 1 & - & - \\
\hline Urban & 2598 & 61.7 & $0.77(0.65-0.91)$ & - & - \\
\hline
\end{tabular}

*Weighted for nonresponse bias to reflect provincial estimates.

†Theme-adjusted odds ratios are adjusted for parental education, parental income and neighbourhood income.

łFully adjusted odds ratios are adjusted for significant risk factors in all 4 theme groups, including lunch and family supper in dietary habits (Table 1), participation in physical activities in activities (Table 2), parental education and neighbourhood income in sociodemographic factors, and frequency of physical education classes in school-based factors (Table 4).

$\$$ Neighbourhood income was estimated by averaging, per school, the postal-code level means of household income (available through the 2001 Canada census) of residential addresses of children attending that school. 
drinks were sold. These children drank an average of 4.0 cans of soda pop per week compared with 3.6 cans drunk by children attending schools without such sales $(p<0.01)$. Children from schools with and without sales of soft drinks consumed an average of 33.5 and $32.5 \mathrm{~g}$ of sucrose per day respectively $(p=0.11)$. Availability of soft drinks at schools was not associated with significantly increased risks of overweight (Table 4).

Children attending schools with more frequent physical education classes were increasingly more likely to have normal body weight. Financial restraints on the purchase of recreation and gymnasium equipment were not statistically associated with increased weight (Table 4).

When we compared obese with normal-weight children, we obtained a model that identified male sex as a significant risk factor for obesity (Table 5). As well, the effects of parents' educational attainment, neighbourhood income, and frequency of physical activity and physical education classes were more pronounced for obesity than for overweight.

\section{Interpretation}

The results of this study show that $32.9 \%$ of grade 5 students in Nova Scotia are overweight and $9.9 \%$ are obese. This rate of overweight is higher than the $26 \%$ found among participants of the same age in the 1996 NLSCY. ${ }^{23}$ Our obesity estimates are more than twice as high as those of 10- and 11-year-old NLSCY participants and about $50 \%$ higher than those of 10- and 11-year-old NLSCY participants residing in Nova Scotia. ${ }^{23}$ It is important to note that we measured children's height and weight, whereas the NLSCY used parental reports of height and weight. Because the latter generally results in overestimation of overweight and obesity, ${ }^{29}$ the actual difference between the rates is likely to be even more pronounced.

Swinburn and associates called for the investigation of risk factors relating to parents, family and school environment. ${ }^{21}$ We found that children from families that eat together regularly are less likely to be overweight or obese. One reason for this is that these children generally eat a more healthy diet. ${ }^{25,30,31} \mathrm{~A}$ second reason is that family meals prevent children from eating in front of the television, which may lead to "mindless eating" and higher energy intake. ${ }^{32-34}$ There may also be broader benefits of better communication and relationships between children and parents resulting from the daily interactions during meals. ${ }^{35}$

In terms of school environment, the association between obesity levels and frequency of physical education classes was striking. This finding supports policies that increase the frequency of physical education classes, such as those recently announced for all elementary schools in Alberta. School lunches represent another opportunity to reduce overweight and obesity. Halting the sales of soft drinks in schools has been suggested to reduce the intake of refined sugars ${ }^{25,35}$ and is an advocated strategy to prevent overweight. ${ }^{36} \mathrm{We}$ observed that children attending schools that sell soft drinks consumed somewhat more soft drinks and sugar, but the amounts were likely insufficient to bring about differences in body weight. Previously we showed that integrated school programs that include more physical education, healthy lunches, health

Table 4: School-based risk factors for overweight among grade 5 students in Nova Scotia

\begin{tabular}{|c|c|c|c|c|c|}
\hline \multirow[b]{2}{*}{ Risk factor } & \multirow{2}{*}{$\begin{array}{c}\text { No. of } \\
\text { students } \\
n=4209\end{array}$} & \multirow{2}{*}{$\begin{array}{c}\text { Weighted } \\
\text { prevalence, } * \%\end{array}$} & \multicolumn{3}{|c|}{ Weighted odds ratio (95\% confidence interval)* } \\
\hline & & & Unadjusted & Theme-adjusted $†$ & Fully adjusted $\neq$ \\
\hline \multicolumn{6}{|l|}{ Lunch provided by } \\
\hline Foodservice company & 1269 & 29.3 & $1.12(0.93-1.34)$ & - & - \\
\hline Staff or volunteers & 540 & 12.3 & $1.02(0.77-1.35)$ & - & - \\
\hline Prepaid lunch program & 658 & 35.6 & $1.05(0.88-1.25)$ & - & - \\
\hline \multicolumn{6}{|l|}{ Available at school } \\
\hline Soft drinks & 658 & 15.3 & $0.99(0.77-1.27)$ & - & - \\
\hline Vending machine(s) & 2229 & 59.2 & $0.90(0.76-1.07)$ & - & - \\
\hline \multicolumn{6}{|l|}{$\begin{array}{l}\text { Frequency of physical } \\
\text { education classes }\end{array}$} \\
\hline$<1.5$ times/wk & 185 & 3.9 & 1 & 1 & 1 \\
\hline$\geq 1.5$ and $<2$ times/wk & 2097 & 49.5 & $0.61(0.43-0.88)$ & $0.61(0.43-0.88)$ & $0.76(0.53-1.10)$ \\
\hline$\geq 2$ times/wk & 1927 & 46.6 & $0.53(0.36-0.76)$ & $0.53(0.36-0.76)$ & $0.61(0.43-0.87)$ \\
\hline \multicolumn{6}{|l|}{ Financial restraints for } \\
\hline Outdoor play equipment & 2352 & 32.8 & $1.08(0.91-1.29)$ & - & - \\
\hline Gymnasium equipment & 1741 & 33.6 & $1.17(0.98-1.40)$ & - & - \\
\hline
\end{tabular}


and nutrition education, training of staff, parental involvement, and a halt to the sales of soft drinks were successful in improving children's diets and reducing overweight by $59 \%$ and obesity by $72 \% .^{24}$

In our study, as in other studies of the effect of risk factors related to children's lifestyle, normal-weight children were more physically active and engaged less in sedentary activities. ${ }^{15-17}$ Similarly in keeping with other studies, we observed a gradient whereby children of socioeconomically disadvantaged families were more likely to be overweight or obese. ${ }^{13,14,23}$ Studies in the United States and Europe have shown neighbourhood differentials with respect to overweight. ${ }^{37-39}$ Our study confirms this in a Canadian setting, with childhood obesity rates that were twice as high in low-

\section{Table 5: Risk factors for obesity among grade 5 students in Nova Scotia}

\begin{tabular}{|c|c|}
\hline Risk factor & $\begin{array}{c}\text { Adjusted odds ratio* } \\
\text { (95\% confidence interval) }\end{array}$ \\
\hline \multicolumn{2}{|l|}{ Lunch } \\
\hline Bring from home & 1 \\
\hline Eat at home & $1.04(0.77-1.40)$ \\
\hline Buy at school & $1.39(1.09-1.77)$ \\
\hline Skips & $1.47(0.77-2.83)$ \\
\hline \multicolumn{2}{|l|}{ Family supper } \\
\hline$<$ once/wk & 1 \\
\hline 1-2 times/wk & $0.88(0.64-1.22)$ \\
\hline 3-4 times/wk & $0.68(0.48-0.96)$ \\
\hline$\geq 5$ times/wk & $0.71(0.53-0.95)$ \\
\hline \multicolumn{2}{|l|}{ Participation in physical activities } \\
\hline$\leq$ twice/week & 1 \\
\hline$>2$ and $\leq 4$ times/wk & $0.81(0.58-1.13)$ \\
\hline$>4$ and $\leq 7$ times $/ \mathrm{wk}$ & $0.77(0.58-1.03)$ \\
\hline$>7$ times/wk & $0.65(0.44-0.97)$ \\
\hline \multicolumn{2}{|l|}{ Sex } \\
\hline Girls & 1 \\
\hline Boys & $1.20(1.01-1.44)$ \\
\hline \multicolumn{2}{|l|}{ Parental education } \\
\hline Completed secondary school or less & 1 \\
\hline Completed community college & $0.79(0.61-1.01)$ \\
\hline Completed university & $0.58(0.43-0.79)$ \\
\hline Completed graduate university & $0.55(0.36-0.83)$ \\
\hline \multicolumn{2}{|l|}{ Neighbourhood income $\dagger$} \\
\hline Lowest one-third & 1 \\
\hline Middle one-third & $0.82(0.61-1.11)$ \\
\hline Highest one-third & $0.50(0.36-0.70)$ \\
\hline \multicolumn{2}{|l|}{$\begin{array}{l}\text { Frequency of physical education } \\
\text { classes at school }\end{array}$} \\
\hline$<1.5 /$ wk & 1 \\
\hline$\geq 1.5$ and $<2 /$ wk & $0.91(0.55-1.52)$ \\
\hline$\geq 2 / \mathrm{wk}$ & $0.54(0.33-0.88)$ \\
\hline
\end{tabular}

* Odds ratios are adjusted for all of the factors listed in the table and are weighted for a nonresponse bias to reflect provincial estimates.

†Neighbourhood income was estimated by averaging, per school, the postal-code level means of household income (available through the 2001 Canada census) of residential addresses of children attending that school. income neighbourhoods as in high-income neighbourhoods. Because of these dramatic differences, children and schools in low-income neighbourhoods should receive priority in public health initiatives to reduce future socioeconomic inequalities in health.

Strengths of our study include the population-based and multidisciplinary approach. Other strengths include measurements of participants' height and weight, the adjustment for nonresponse bias and the consideration of various potential confounders. Although most of the questions and questionnaires we administered were validated, responses remain subjective and prone to error. An additional limitation is the cross-sectional design, which introduces uncertainties regarding the sequence of cause and effect of the observed associations. Longitudinal studies overcome this limitation and will strengthen the evidence regarding risk factors for childhood overweight and obesity.

In summary, we have shown that school- and familybased factors are associated with an increased risk of childhood overweight and obesity, and therefore they present opportunities for targeting this problem. Recommendations for action include more physical education classes and promotion of healthy lunches at schools and of family suppers at home. Preventive public health actions should be targeted first toward low-income neighbourhoods.

This article has been peer reviewed.

From the Department of Public Health Sciences, University of Alberta, Edmonton, Alta. (Veugelers) and the Department of Community Health and Epidemiology, Dalhousie University, Halifax, NS (Veugelers, Fitzgerald)

Competing interests: None declared.

Contributors: Paul Veugelers, as the principal investigator of the CLASS project, conceived and designed the study. He and Angela Fitzgerald both contributed substantially to the analysis and interpretation of data, revised the manuscript critically for important intellectual content and read and approved the final version.

Acknowledgements: We thank all of the grade 5 students, parents and schools for their participation in the CLASS project. We thank all of the research assistants and public health staff who assisted in the data collection, Jason Liang for the data management of the project, and Cynthia Colapinto for her feedback on the manuscript.

This research was funded by a Canadian Population Health Initiative operating grant and through a Canadian Institutes of Health Research New Investigator Award to Dr. Veugelers.

\section{References}

1. Ebbeling CB, Pawlak DB, Ludwig DS. Childhood obesity: Public-health crisis, common sense cure. Lancet 2002;360:473-82.

2. Andersen RE. The spread of the childhood obesity epidemic [commentary]. CMA7 2000;163:1461-2.

3. Tremblay MS, Willms JD. Secular trends in the body mass index of Canadian children. CMA7 2000;163:1429-33.

4. Tremblay MS, Katzmarzyk PT, Willms JD. Temporal trends in overweight and obesity in Canada, 1981-1996. Int 7 Obes Relat Metab Disord 2002;26:538-43.

5. Tremblay MS, Inman JW, Willms JD. Relationships between physical activity, self esteem, and academic achievements in ten- and eleven-year-old children. Pediatr Exer Sci 2000;11:312-23.

6. Hesketh K, Wake M, Waters E. Body mass index and parent-reported selfesteem in elementary school children: evidence for a causal relationship. Int 7 Obes Relat Metab Disord 2004;28:1233-7.

7. Must A, Strauss RS. Risks and consequences of childhood and adolescent obesity. Int 7 Obes Relat Metab Disord 1999;23(Suppl 2):S2-11.

8. Dietz WH. Overweight in childhood and adolescence. $N$ Engl $\mathcal{F}$ Med 2004; 350:855-7. 
9. Manson JE, Bassuk SS. Obesity in the United States. A fresh look at its high toll. FAMA 2003;289:229-30.

10. Fontaine KR, Redden DT, Wang C, Westfall AO, Allison DB. Years of life lost due to obesity. FAMA 2003;289:187-93.

11. Katzmarzyk PT, Janssen I. The economic costs associated with physical inactivity and obesity in Canada: An update. Can 7 Appl Physiol 2004;29:90-115.

12. Nicklas T, Johnson R. Position of the American Dietetic Association: dietary guidance for healthy children ages 2 to 11 years. 7 Am Diet Assoc 2004;104:660-77.

13. Katzmarzyk PT, Ardern CI. Overweight and obesity mortality trends in Canada, 1985-2000. Can 7 Public Health 2004;95:16-20.

14. Power C, Graham H, Due P, Hallqvist J, Joung I, Kuh D, et al. The contribution of childhood and adult socioeconomic position to adult obesity and smoking behaviour: an international comparison. Int 7 Epidemiol 2005;34:335-44.

15. Lamerz A, Kuepper-Nybelen J, Wehle C, Bruning N, Trost-Brinkhues G, Brenner $\mathrm{H}$, et al. Social class, parental education, and obesity prevalence in a study of six-year-old children in Germany. Int 7 Obes Relat Metab Disord 2005;29:373-80.

16. Tremblay MS, Willms JD. Is the Canadian childhood obesity epidemic related to physical inactivity? Int 7 Obes Relat Metab Disord 2003;27:1100-5.

17. Hancox RJ, Milne BJ, Poulton R. Association between child and adolescent television viewing and adult health: a longitudinal birth cohort study. Lancet 2004:17;364:257-62.

18. Graf C, Koch B, Dordel S, Schindler-Marlow S, Icks A, Schuller A, et al. Physical activity, leisure habits and obesity in first-grade children. Eur 7 Cardiovasc Prev Rehabil 2004;11:284-90.

19. Willms JD. Early Childhood Obesity: A call for early surveillance and preventive measures. CMAJ 2004;171:243-4.

20. Canning PM, Courage ML. Frizzell. Prevalence of overweight and obesity in a provincial population of Canadian preschool children. CMA7 2004;171:240-2.

21. Swinburn B, Gill T, Kumanyika S. Obesity prevention: a proposed framework for translating evidence into action. Obes Rev 2005;6:23-33.

22. Gaudette LA, Altmayer CA, Wysocki M, Gao RN. Cancer incidence and mortality across Canada. Health Rep 1998;10:51-66.

23. Willms JD, Tremblay MS, Katzmarzyk PT. Geographic and demographic variation in the prevalence of overweight Canadian children. Obes Res 2003;11:668-73.

24. Veugelers PJ, Fitzgerald AL. Effectiveness of school programs in the prevention of childhood obesity. Am 7 Public Health 2005;95:432-5.

25. Veugelers PJ, Fitzgerald AL, Johnston E. Dietary intake and risk factors for poor diet quality among children in Nova Scotia. Can 7 Public Health 2005;96:212-6.

26. Cole TJ, Bellizzi MC, Flegal KM, Dietz WH. Establishing a standard definition for child overweight and obesity worldwide: international survey. $B M 7$ 2000;320:1240-3.

27. Rockett HR, Wolf AM, Colditz GA. Development and reproducibility of a food frequency questionnaire to assess diets of older children and adolescents. 7 Am Diet Assoc 1995;95:336-40.

28. Statistics Canada. National longitudinal survey of children and youth (NLSCY). Available: www.statcan.ca/cgi-bin/imdb/p2SV.pl?Function=get Survey\&SDDS $=4450 \&$ lang $=\mathrm{en} \& \mathrm{db}=\mathrm{IMDB} \& \mathrm{db} g=\mathrm{f} \& \mathrm{adm}=8 \& \mathrm{dis}=2$ (accessed $2005 \mathrm{Jul} 26)$.

29. Burton P, Lethbridge L, Osberg L, Phipps S. Measuring obesity in young children. Can Public Policy 2004;30:349-64.

30. Gillman MW, Rifas-Shiman SL, Frazier L, Rockett HRH, Camargo CA Field AE. Family dinner and diet quality among older children and adolescents. Arch Fam Med 2000;9:235-40.

31. Neumark-Sztainer D, Hannan PJ, Story M, Croll J, Perry C. Family meal patterns: Associations with sociodemographic characteristics and improved dietary intake among adolescents. 7 Am Diet Assoc 2003;103:317-22.

32. Robinson TN. Television viewing and childhood obesity. Pediatr Clin North Am 2001;48:1017-25

33. Caroli M, Argentieri L, Cardone M, Masi A. Role of television in childhood obesity prevention. Int 7 Obes Relat Metab Disord 2004;28(Suppl 3):S104-8.

34. National Center for Addiction and Substance Abuse at Columbia University. The importance of family dinners. New York: The Center; 2003. Available: www.casacolumbia.org/Absolutenm/articlefiles/Family_Dinners_9_03_03.pdf (accessed 2005 Mar 21).

35. Swinburn BA, Caterson I, Seidell JC, James WP. Diet, nutrition and the prevention of excess weight gain and obesity. Public Health Nutr 2004;7(1A):123-46.

36. Fried EJ, Nestle $M$. The growing political movement against soft drinks in schools. FAMA 2002;288:2181.

37. Ellaway A, Anderson A, Macintyre S. Does area of residence affect body size and shape? Int 7 Obes Relat Metab Disord 1997;21:304-8.

38. Van Lenthe FJ, Mackenbach JP. Neighbourhood deprivation and overweight: the GLOBE study. Int 7 Obes Relat Metab Disord 2002;26:234-40.

39. Robert SA, Reither EN. A multilevel analysis of race, community disadvantage, and body mass index among adults in the US. Soc Sci Med 2004;59:2421-34.

Correspondence to: Dr. Paul J. Veugelers, Department of Public Health Sciences, Faculty of Medicine and Dentistry, University of Alberta, 13-106D Clinical Sciences Building, Edmonton AB T6G 2G3; fax 780 492-0364; paul.veugelers@ualberta.ca 